\title{
¿Está constitucionalmente prohibido el arbitramento internacional de inversiones en Ecuador?
}

\begin{abstract}
Is international investment arbitrament constitutionally prohibited in Ecuador?
\end{abstract}

\author{
Arbitramento internacional de \\ investimentos no Equador é \\ constitucionalmente proibido?
}

María de los Ángeles Arias Murrieta*

DOI: 10.5294/dika.2021.30.2.5 


\section{Resumen}

La prohibición del sometimiento a instancias de arbitraje internacional en caso de disputas derivadas de la suscripción de instrumentos internacionales genera un ambiente de inestabilidad para las empresas foráneas que desean invertir en el Ecuador. Este artículo aborda la problemática en relación con la interpretación y aplicación del artículo 422 de la Constitución del Ecuador. Por medio de un enfoque cualitativo se analiza si esta cláusula cumple los parámetros para calificar si ha caído en desuso y, en caso de no cumplirlos, si la limitación al sometimiento de arbitraje a jurisdicción internacional es absoluta. Finalmente, se analiza la posibilidad de una interpretación flexible que permita al Ecuador suscribir tratados internacionales de inversión que se sometan a tribunales arbitrales internacionales.

\section{Palabras clave}

Tratados bilaterales de inversión; desuso; mutación constitucional; reformas informales; arbitraje internacional; soberanía. 


\section{Abstract}

The prohibition to submit to international arbitration bodies in the event of disputes arising from the signing of international instruments creates an environment of instability for foreign companies that wish to invest in Ecuador. This article addresses the problem of the interpretation and application of article 422 of the Constitution of Ecuador. Through a qualitative approach to the norm, it is analyzed whether this clause meets the parameters to qualify whether it has fallen into disuse, if it does not meet them, whether the limitation to submitting arbitration to international jurisdiction is absolute. Finally, the possibility of a flexible interpretation that allows Ecuador the possibility of signing international investment treaties submitted to international arbitration tribunals is analyzed.

\section{Keywords}

Bilateral investment treaties; disuse; constitutional mutation; informal reforms; international arbitration; sovereignty. 


\section{Resumo}

A proibição de submissão a instâncias de arbitragem internacional em caso de controvérsias derivadas da assinatura de instrumentos internacionais, cria um ambiente de instabilidade para as empresas estrangeiras que desejam investir no Equador. Este artigo aborda o problema de interpretação e aplicação do artigo 422 da Constituição do Equador. Por meio de uma abordagem qualitativa, analisa-se se essa cláusula atende aos parâmetros para qualificar se caiu em desuso e, caso contrário, se a limitação à submissão da arbitragem à jurisdição internacional é absoluta. Finalmente, analisa-se a possibilidade de uma interpretação flexível que permita ao Equador assinar tratados internacionais de investimento submetidos a tribunais arbitrais internacionais.

\section{Palavras-chave}

Tratados bilaterais de investimento; desuso; mutação constitucional; reformas informais; arbitragem internacional; soberania. 
Sumario: Introducción. 1. Interpretación absoluta. 1.1. Soberanía desde el punto de vista del derecho internacional. 1.2. Defectos y beneficios del sistema arbitral internacional. 2. Cambio constitucional informal. 2.1. Desuso constitucional. 2.1.1. Antecedentes. 2.1.2. Elementos característicos del desuso constitucional. 2.1.3 Desuso constitucional prematuro. 2.1.4. Defectos del cambio informal por desuso. 2.1.5 ¿Desuso constitucional del artículo 422? 3. Interpretación flexible. 3.1. Análisis de la Sentencia C-252/2019 de la Corte Constitucional colombiana. Conclusión. Bibliografía.

\section{Introducción}

La interpretación del artículo 422 de la Constitución prohíbe al Estado ecuatoriano suscribir tratados bilaterales de inversión (TBI), en los que se ceda la jurisdicción soberana a instancias del arbitraje internacional, lo cual se refleja directamente en inseguridad jurídica para el inversionista extranjero. El citado artículo establece lo siguiente:

Art. 422. No se podrá celebrar tratados o instrumentos internacionales en los que el Estado ecuatoriano ceda jurisdicción soberana a instancias de arbitraje internacional, en controversias contractuales o de índole comercial, entre el Estado y personas naturales o jurídicas privadas. Se exceptúan los tratados e instrumentos internacionales que establezcan la solución de controversias entre Estados y ciudadanos en Latinoamérica por instancias arbitrales regionales o por órganos jurisdiccionales de designación de los países signatarios. No podrán intervenir jueces de los Estados que como tales o sus nacionales sean parte de la controversia. En el caso de controversias relacionadas con la deuda externa, el Estado ecuatoriano promoverá soluciones arbitrales en función del origen de la deuda y con sujeción a los principios de transparencia, equidad y justicia internacional. ${ }^{1}$

De acuerdo con el anterior artículo, el cual fue incluido en la Constitución del año 2008, se iniciaron las denuncias de los TBI por parte del gobierno ecuatoriano debido a que, a partir de ese momento, se encontraban en contra de la norma constitucional, lo que producía un ambiente de incertidumbre que ocasionó el desestímulo de la inversión extranjera. En aquel momento histórico se permitió la inclusión de este texto, puesto que existía el peligro de la imposición de condenas por parte del Centro Internacional de Arreglo de Diferencias Relativas a Inversiones (Ciadi), con altas cuantías en contra del Estado ecuatoriano.

Desde aquel entonces, Ecuador se halla en desventaja ante un proceso de globalización que implica el sometimiento del arbitraje de inversión ante potenciales controversias entre los inversionistas y los Estados. Como resultado de la rigidez de esta norma surgieron interpretaciones que flexibilizaron su aplicación, con el propósito de permitir la suscripción de nuevos acuerdos internacionales de inversión.

1 Asamblea Nacional Constituyente del Ecuador, Constitución de la República del Ecuador, Quito, 2008, art. 422. 
De ese modo, con el cambio de Gobierno en 2017 -y habiendo renunciado a esa fecha a todos los TBI-, los nuevos actores políticos produjeron interpretaciones distintas al tenor literal de la norma y con aprobación de la Corte Constitucional. De esta manera, sin cambiar el texto de la norma, se permitió la suscripción y la adhesión a instrumentos internacionales en los que el Estado ecuatoriano se sometió a jurisdicción internacional. El primero de estos fue el "Acuerdo Comercial entre la Unión Europea y sus Estados miembros por una parte, y los Estados de Colombia y el Perú por otra, para tener en cuenta la adhesión de Ecuador". ${ }^{2}$

Pese a la literalidad de la norma constitucional y para agravar el problema interpretativo, el órgano legislativo reformó en 2018 el Código Orgánico de la Producción, Comercio e Inversiones (Copci), en el que se estableció la posibilidad de pactar arbitraje internacional por parte del Estado ecuatoriano. Cabe aclarar que, desde su reforma, esta ley se contradice con la norma constitucional de máxima jerarquía, en tanto que la justificación para su aprobación se fundamentó en que la controversia no surgiría de un TBI, sino de un contrato de inversión, lo que otorgaría más seguridades al Estado ecuatoriano.

Solo una semana después de ser aprobada la reforma del Copci, en la sesión 524 de la Asamblea Nacional se aprobó presentar una acción de interpretación a la Corte Constitucional en el siguiente objetivo:

\begin{abstract}
Se interprete el primer inciso del artículo 422 de la Constitución, sobre el alcance de la prohibición para que se celebre tratados, en los que el Estado ceda jurisdicción soberana a instancias de arbitraje internacional, en controversias contractuales o de índole comercial entre el Estado y personas naturales o jurídicas privadas, cuando se celebren tratados de protección de inversiones en los que las controversias no sean contractuales ni comerciales. ${ }^{3}$
\end{abstract}

Es preciso resaltar que la acción de interpretación planteada a la Corte Constitucional hasta el día de hoy no ha sido resuelta. En la actualidad, dado que esta norma interpretada al tenor de lo literal desincentiva la inversión extranjera, y que los actores políticos -el Legislativo, el Ejecutivo y la Corte Constitucional-han rechazado tácitamente su aplicación, corresponde realizar un análisis de las posibilidades de interpretación que puedan resolver el problema que genera la interpretación literal.

De esa forma, este análisis de interpretación normativa se presenta un trilema. Por un lado, se puede interpretar que la prohibición del artículo 422 se debe entender al tenor de lo literal y, así, absoluta y restrictiva; por otro lado,

2 Parlamento Europeo, Acuerdo comercial entre la Unión Europea y Colombia y Perú. Evaluación europea de la aplicación, Estrasburgo, Servicio de Estudios del Parlamento Europeo, 2018, p. 11.

3 Corte Constitucional del Ecuador, “IC - Interpretación de Normas Constitucionales, 0002-18-IC", 16 de agosto de 2018, https://portal.corteconstitucional.gob.ec/FichaCausa.aspx?numcausa=0002-18-IC 
se puede interpretar que esta norma se encuentra en desuso constitucional, el cual consiste en la inaplicación constante de una norma que cumpla ciertos parámetros mínimos; y una tercera interpretación se fundamenta en que el artículo 422 contiene una prohibición relativa y que no debe ser entendida al tenor de lo literal y que, de tal forma, al suscribir estos acuerdos no se cede soberanía, sino que se ejerce.

Esta investigación analiza el artículo 422 de la Constitución, con base en una perspectiva de derecho comparado que desarrolla lineamientos para el sometimiento a jurisdicción arbitral internacional. Desde su origen, la norma tiene por objeto la legitimación y protección ante condenas injustificadas y con cuantías desproporcionadas hacia el Estado ecuatoriano. Sin embargo, la consecuencia de una norma tan rígida interpretada literalmente causa problemas económicos de similar gravedad a los laudos que se buscan evitar, dado que previene casi absolutamente la inversión extranjera.

Es por esta problemática que alcanzar un punto medio entre ambas posturas se vuelve necesario, en especial si se considera la tendencia académica actual del derecho internacional de inversiones, a partir de la Sentencia C-252 de $2019^{4}$ del Acuerdo de Protección Recíproca de Inversiones entre Francia y Colombia, la cual establece parámetros modernos más flexibles para evitar laudos que permitan condenas desproporcionadas, sin cerrar la posibilidad de someterse a centros de arbitraje internacional.

\section{Interpretación absoluta}

El trilema que se presenta por las potenciales interpretaciones que se le puedan atribuir a esta prohibición constitucional se produce por las varias actuaciones contradictorias de la última década, tanto de los actores políticos como de la Corte Constitucional ecuatoriana. Estos han permitido una interpretación restrictiva y absoluta utilizándola además como fundamento de denuncia de todos los TBI suscritos por Ecuador; incluso, cambian de criterio sin una clara motivación.

Es de mencionar que, por esta forma incongruente de uso normativo, dicha prohibición permite observar la postura de una interpretación absoluta. Por este motivo, se debe hacer referencia a la cesión de jurisdicción soberana y, especialmente, al concepto de soberanía desde el aspecto externo, dado que esta ha sido la fundamentación por la cual se ha desarrollado la prohibición constitucional de someterse a arbitraje internacional de inversiones.

4 Colombia, Corte Constitucional, Sentencia C-252 de 6 de julio de 2019, Sala Plena, M. P. Carlos Bernal Pulido, https://www.corteconstitucional.gov.co/relatoria/2019/c-252-19.htm 


\subsection{Soberanía desde el punto de vista del derecho internacional}

El concepto de soberanía puede ser entendido desde dos aspectos, el interno y el externo. Para el presente estudio se hace referencia únicamente al concepto de soberanía desde el aspecto externo que, según Carpizo: "Significa que un pueblo independiente y supremo se presenta en el consorcio universal de naciones, entra en relaciones con sus pares; es el mismo principio que rige la vida interna de la nación, solo que proyectado hacia afuera del Estado".$^{5}$

Por su parte, Hillgruber determinó que "la soberanía como concepto de derecho internacional está apelando a una autoridad originaria y universal de que gozan los Estados, independientes unos de otros, pero iguales en derechos, sujetos inmediatos del derecho internacional" ${ }^{6}$

Desde el punto de vista del derecho internacional, la acepción de soberanía consiste en que el Estado voluntariamente toma la decisión de formar parte de un conjunto de naciones que se comprometen a seguir un ordenamiento jurídico distinto al nacional. En este se destaca que cada Estado se desarrolla de forma independiente y que ninguno tiene injerencia en relación con las decisiones del otro.

Sin embargo, existen discusiones relacionadas con el antagonismo que hay entre soberanía de un Estado y el derecho internacional. Autores como Kelsen eran críticos del concepto de soberanía al punto de proponer como solución la eliminación de dicho término, pues no era posible reconocerlo, al contrario, consistía en un supuesto fácil de manipular a favor de conveniencias políticas.

Cabe señalar que de la coexistencia del derecho interno y el derecho internacional nacen las posturas dualista y monista. La primera plantea al derecho interno y al derecho internacional como ordenamientos jurídicos independientes y equivalentes. En contraste, la monista, de la cual Kelsen fue partidario, determinó que el derecho interno y externo coexistían, y que ante un conflicto que pudiera existir entre el ordenamiento jurídico interno y el externo prevalecería lo que se elija a nivel interno.

En este punto en particular, Kelsen no estableció cuál de los dos derechos debía primar, sin embargo, Heller, que también era partidario del monismo, defendió la tesis del derecho interno sobre el externo. Para este autor, toda instancia a la que se haya sometido un Estado debe estar siempre limitada por la soberanía

$5 \quad$ Jorge Carpizo, “La soberanía del pueblo en el derecho interno y en el internacional”, en Revista de Estudios Políticos (Nueva Época) 28 (1982), p. 201.

6 Cristian Hillgruber, "Soberanía. La defensa de un concepto jurídico", en inDret Revista para el Análisis del Derecho 1 (2009), p. 8. 
de cada Estado, su participación siempre estará sujeta a su voluntad. ${ }^{7}$ Hoy en día, en Ecuador existe una marcada postura monista, debido a que la decisión de suscribir un instrumento internacional y someterse al ordenamiento jurídico internacional se limita a lo contemplado por el derecho interno.

Ahora bien, si se retoma el contexto histórico para entender el origen de la inserción de la prohibición de ceder jurisdicción soberana en el texto constitucional del año 2008, se puede deducir que se dio como una respuesta a la condena impuesta al Estado ecuatoriano por el tribunal arbitral del Ciadi en el año 2006, por 1.796 millones de dólares estadounidenses. De ahí que, como rechazo a este laudo, se insertó en el texto de la Constitución esta prohibición, a fin de facilitar un mecanismo que permitiera denunciar todos los acuerdos internacionales en materia de inversión. Lo anterior para evitar que se repitieran condenas de tan alta cuantía en contra del Estado ecuatoriano.

La postura del Gobierno se fundamentó en que se estaba "defendiendo el principio de la soberanía jurisdiccional" ${ }^{8}$ Si se revisa la época de elaboración de la Constitución, específicamente en la mesa 9 de la Asamblea Constituyente del Ecuador, allí se discutió la redacción del artículo 422. Al respecto, el asambleísta Francisco Velasco manifestó lo siguiente:

En el tema de la OXY, por encima del convenio entre Estado-empresa, está un convenio Internacional, mediante el cual se obliga al Ecuador por el Ciadi a ceder soberanía en razón del Tratado de Protección de Inversiones. El artículo no pretende dejar de celebrar contratos con empresas privadas sino para no hacerle ceder jurisdicción soberana al Estado Ecuatoriano. ${ }^{9}$

Es indiscutible que la voluntad del constituyente fue crear una prohibición expresa para que el Ecuador no pueda ser sometido a arbitramento internacional, indistintamente de si se trata de materia comercial o contractual. De tal manera, lo que se pretendía evitar es que el Estado celebre instrumentos internacionales en los cuales se establezcan cláusulas paraguas que puedan incurrir en penas perjudiciales y que, a su vez, atenten con la sostenibilidad fiscal del Estado.

Con estas posturas se buscaba establecer que el Ecuador, cuando firmó los tratados bilaterales de inversiones, se había encontrado forzado a ceder soberanía a instancias internacionales. A partir de este argumento se vuelve necesario explicar qué sucede al respecto de la soberanía cuando un Estado decide sujetarse al ordenamiento jurídico internacional.

$7 \quad$ Leticia Vita, “Soberanía y derecho internacional en el pensamiento jurídico de Weimar”, en Journal of International Law 3 (1) (2012), pp. 7-24.

8 Paul Mena Erazo, "Ecuador pone fin a tratados bilaterales de inversiones", en BBC News, 2010, https://www. bbc.com/mundo/economia/2010/09/100915_ecuador_fin_tratados_bilaterales_inversiones_jp

9 Centro de Derechos Económicos y Sociales, "Amicus curiae para impedir nuevos TBI", en CDES, 2020, https:// cdes.org.ec/web/amicus-curiae-para-impedir-nuevos-tbi/ 
En primer lugar, se debe resaltar que un Estado siempre será independiente respecto de otros y sus ordenamientos jurídicos. Por lo tanto, el Estado, en ejercicio de su autonomía, decide actuar voluntariamente y ser parte del conjunto de naciones de forma igualitaria, sin que ninguno tenga más poder o autoridad que el otro. Segundo, cuando un Estado crea normas debido a las obligaciones que ha asumido por ser parte de este ordenamiento jurídico internacional, esto no quiere decir que renuncia a su soberanía, por el contrario, se encuentra en uso de sus facultades para obligarse internacionalmente. ${ }^{10}$

Esto significa que, en el momento en que el representante de un Estado, en este caso del Ecuador, suscribió un instrumento internacional, lo realizó voluntariamente y contempló las facultades otorgadas por su mandante y por las regulaciones del derecho interno, mas no fue obligado o impuesto, como se fundamentó al momento de agregar el articulado en la Asamblea Constituyente. Es una potestad del Estado formar parte de este ordenamiento jurídico internacional, así como retirarse de él.

Para la expresión de prohibición de cesión de soberanía cabe la primera interpretación, una amplia, según la cual, cualquier tratado de protección recíproca de inversiones que contenga un mecanismo de solución de controversias con sede internacional o distinto a someterse a la jurisdicción del Estado ecuatoriano implica la cesión de jurisdicción soberana.

Esta interpretación amplia es considerada errada, puesto que cuando el presidente, la Asamblea Nacional y la Corte Constitucional aprueban y ratifican un tratado internacional ejercen soberanía, mas no la ceden. La única forma de entender que se ha cedido jurisdicción soberana se fundamenta en que se entregue permanente e irrevocablemente una parte del poder jurisdiccional a un centro de solución de controversias internacionales.

No obstante, detrás del artículo 422 existe una preocupación y fundamento legítimo acerca de que el Estado suscriba TBIS que contengan mecanismos de resolución de controversias entre inversionista y Estado: que la suscripción de estos acuerdos contraríe principios constitucionales y, como consecuencia, pueda resultar en un detrimento irrazonable y desproporcionado del patrimonio público.

Es importante destacar que entre los países con más demandas provenientes de conflictos originados principalmente por TBI se halla Ecuador, junto a Argentina, Venezuela, México, Bolivia y Perú; este grupo constituye un $73 \%$ del total de demandas de América Latina y el Caribe. Ecuador forma parte de las naciones que han sido condenadas a pagar a empresas inversoras las indemnizaciones más elevadas de la región. El caso más relevante es el de Occiden-

10 Hillgruber, "Soberanía. La defensa de un concepto jurídico", op. cit. 
tal, pues se resolvió una condena de 2.300 millones de dólares que luego fue reducida a 1.061 millones de dólares. ${ }^{11}$

\subsection{Defectos y beneficios del sistema arbitral internacional}

En la actualidad, el sistema de arbitraje de inversiones se encuentra forzado a realizar reformas sustanciales, la presión proviene sobre todo, de los países en desarrollo que han sido condenados al pago de indemnizaciones de altas cuantías por parte de los inversores. Para 2020 existían más de 3.000 acuerdos de inversión y aproximadamente 1.000 demandas interpuestas ante los tribunales de inversión. Según los informes, alrededor de un 30 \% de esas demandas han sido interpuestas contra países de América del Sur que han sido condenados con el pago de aproximadamente 22.000 millones de dólares en indemnizaciones. ${ }^{12} \mathrm{Sin}$ duda, esta situación ha causado un marcado rechazo en naciones de la región al suscribir o renovar nuevos acuerdos o TBI.

No es un secreto afirmar que existen varias posturas a favor y en contra del sistema arbitral internacional; para los defensores del sistema, este promueve la rendición de cuentas y la participación democrática. A través de los laudos arbitrales se crean principios del derecho administrativo transnacional y estándares normativos internacionales. ${ }^{13}$ Además, le atribuyen al sistema la promoción de la equidad y el Estado de derecho. La anterior postura se basa en que un inversor no tendría que someterse ante una autoridad nacional y sería un ente neutral como el sistema de controversias internacional que resuelva el conflicto. ${ }^{14}$

Por otra parte, entre los planteamientos opuestos sobresale el de Gus Van Harten, quien comentó que "el Régimen de inversiones basado en TBI incorpora uno de los sistemas más poderosos de adjudicación internacional, este sistema reasigna poderes de los estados a empresas multinacionales y de cortes nacionales a tribunales arbitrales internacionales". ${ }^{15}$ Incluso, Van Harten criticó la postura que establece que el sistema arbitral promueve la equidad y el Estado de derecho, puesto que esta posición representa estándares de equidad procesal e independencia, los que no necesariamente se logran con el arbitraje de inversión. ${ }^{16}$

11 ISDS América Latina, “Impactos ISDS”, 2019, https://isds-americalatina.org/en-numeros/

12 Jimena Sierra, "Los riesgos del ISDS en tiempos de pandemia", Ámbito Jurídico, 2020, https://www.ambitojuridico.com/noticias/etcetera/educacion-y-cultura/los-riesgos-del-isds-en-tiempos-de-pandemia

13 Thomas Schultz y Cédric Dupont, "Investment arbitration: Promoting the rule of law or over-empowering investors? A quantitative empirical study", en The European Journal of International Law, 25 (4) (2015), pp. 1148-1168.

14 Gus Van Harten, "Five justifications for investment treaties: A critical discussion", en Forthcoming 2 (1) (2010), pp. 1-32.

15 Ibid., p. 1.

16 Idem. 
Otro problema fundamental del sistema es la falta de independencia, especialmente resalta el problema que acarrea la designación de los árbitros. Dichas designaciones se realizan por medio de organizaciones que son las autoridades nominadoras en controversias de inversión. Normalmente, estas instituciones tienen poder dentro del sistema y son las encargadas de proponer un listado de árbitros en caso de que las partes no se pongan de acuerdo. Sumado a esto, puede ejercer supervisión en las reglas de arbitrajes o sobre ciertos laudos en particular, el problema es que se otorga a funcionarios poderes exorbitantes al momento de resolver temas claves del arbitraje. Estos funcionarios responden a poderes de una organización $y$, por ende, no pueden ser considerados imparciales o neutrales. ${ }^{17}$

Del mismo modo, Van Harten estableció que el mecanismo de resolución de controversias entre inversores y Estado se fundamenta en un proceso de protección para el inversor extranjero. ${ }^{18}$ Por regla general, beneficia generosamente al inversor y no se le imponen las mismas obligaciones que se le atribuyen a los Estados. El inversionista extranjero tiene la facultad de demandar a un Estado si considera que se ha actuado de manera injusta al imponer por parte de este actos judiciales, regulaciones o simplemente si ha obrado de forma incorrecta contra el inversionista; como respuesta, el sistema otorga derechos especiales. El lenguaje ambiguo que se ha manejado en los TBI ha causado que los árbitros otorguen a los inversionistas compensaciones y, asimismo, se les ha dado la facultad para otorgarlas. En este sentido, el arbitraje es utilizado por el inversionista como un fin para lucrarse con fondos públicos.

A pesar de las condenas desproporcionadas y de los múltiples defectos expuestos, el sistema arbitral internacional de inversiones se sigue desarrollando de una manera que ha sido criticada como poco transparente por la confidencialidad de los procesos. Lo anterior, debido a que se está ante procesos en los que se involucran fondos públicos, no obstante, en la mayoría de los casos se establece que estos procedimientos deben ser confidenciales, lo cual es contradictorio.

Ahora bien, si se observan las reglas de procedimiento de centros de arbitrajes internacionales, por ejemplo, el reglamento de la Corte de Arbitraje Internacional de Londres, en su artículo 30, este contempla la confidencialidad de todos los laudos, documentación y proceso. En contraste, el reglamento de la Cámara de Arbitraje Internacional de París, en su artículo 2, establece que las partes deberán aceptar la confidencialidad del proceso; el reglamento de arbitraje de la Cámara del Instituto de Arbitraje de la Cámara de Comercio de Estocolmo, 
en su artículo 20, numeral 3, determina que el tribunal arbitral "asegurará la confidencialidad del arbitraje".

Entonces, resulta imperativo que los procesos sean abiertos y públicos, puesto que los ciudadanos de una nación deben conocer todas las controversias en las que el patrimonio del Estado sea potencialmente afectado. Estos procedimientos, a simple vista, no son transparentes $y$, muchas veces, permiten suponer que es un sistema hecho al servicio de inversionistas, dadas las elevadas condenas derivadas de interpretaciones que no justifican un detrimento patrimonial de tales proporciones. Sin embargo, a esta crisis del sistema es necesario atribuirle la responsabilidad de los Estados al momento de negociar y aprobar los tratados por parte de los organismos de control.

Finalmente, no se puede dejar a un lado el conflicto existente entre la incompatibilidad de los TBI y la posibilidad de vulneración de derechos humanos. En el pasado, en la suscripción de los TBI se privilegiaban y reglamentaban principalmente los derechos económicos, mientras que los derechos humanos eran dejados en segundo plano. El Estado debe buscar el equilibrio entre el respeto al sometimiento al derecho internacional y la protección del Estado social de derecho. Tal como lo expresó Solórzano, los TBI deben tener en cuenta los derechos humanos, por dos razones:

La primera tiene que ver con que los tratados de derecho internacional público deben interpretarse de manera sistemática [...] dentro de un arbitramento se debería analizar no solo la norma a interpretar (TBI) sino, todas aquellas que estén ligadas al asunto en litigio [...] la segunda es que el estado es un ente público encargado de velar y proteger a los individuos, por lo tanto, resulta erróneo implementar una jurisdicción alejada [de] la realidad en materia de derechos (humanos o fundamentales). ${ }^{19}$

\section{Cambio constitucional informal}

Para iniciar el estudio de cambios constitucionales informales, se deben conocer cuáles son los mecanismos formales para realizar estas modificaciones. La Constitución del Ecuador establece, en los artículos 441, 442 y 444, los mecanismos formales para modificar el texto constitucional, estos son: reforma, enmienda y asamblea constituyente. Con referencia a las reformas constitucionales formales, Richard Albert y Carlos Bernal consideraron que "existe una modificación en el conjunto de normas constitucionales válidas si una o más disposiciones constitucionales escritas nuevas son promulgadas creando un

19 Juan Felipe Solórzano Quintero, “Los tratados bilaterales de protección de inversiones y su sometimiento a (2017), p. 236. 
nuevo texto constitucional o enmienda formal de una Constitución".$^{20}$ Estos procesos modificatorios formales consisten en reglas prescritas que modifican las normas textualmente en la constitución y reemplazan o amplían un texto existente.

Es necesario aclarar que estos cambios formales no son los únicos que modifican la Constitución, también existen modificaciones informales o mutaciones constitucionales. Al respecto, Albert señaló que "la reforma informal hace referencia a los cambios en el sentido de las disposiciones constitucionales sin que ello corresponda a un cambio en el texto". ${ }^{21}$ La diferencia fundamental entre el cambio formal e informal radica en que, mientras el primero modifica textualmente la Constitución, el segundo solo modifica la interpretación de la norma constitucional.

En ese orden de ideas, los cambios informales son alteraciones constitucionales que suelen ser frecuentes en los Estados. En la mayoría de los casos se presentan porque no se puede establecer un significado permanente a las normas constitucionales; siempre dependerán del contexto normativo y de la realidad política en la que se encuentre una sociedad. Entre tanto, decir que una norma no puede evolucionar en su significado sería determinar que una realidad social no cambia y se mantiene estática con el paso de los años. ${ }^{22}$ Para justificar la existencia de las reformas constitucionales informales, Heather Gerken determinó que el cambio informal ocurre por lo complicado que es modificar formalmente una norma constitucional..$^{23}$ Si reformar la Constitución fuera un trabajo simple, no se estuviera ante la inminente carga que lleva estar frente a un cambio informal.

Las primeras modificaciones surgieron de las contradicciones entre normas constitucionales y las diversas realidades jurídicas; esta situación entró en conflicto con la corriente positivista al no encontrarse una solución a estos problemas desde la luz de los preceptos jurídicos. ${ }^{24}$ La doctrina tradicional establecía que las mutaciones son mecanismos inverosímiles y carentes de validez jurídica, en tanto que lo único que puede reformar una constitución es la asamblea constituida por representantes de la nación cuando surge la necesidad de adaptar la norma constitucional a la realidad política. ${ }^{25}$

20 Richard Albert y Carlos Bernal, Cambio constitucional informal, Bogotá, Universidad Externado de Colombia, 2017, pp. 10-11.

21 Richard Albert, “Los métodos de la reforma informal”, en Revista Latinoamericana de Derecho 3 (2019), p. 30.

22 Adriano Sant'Ana, "Mutación constitucional y concreción normativa: cómo la estructura de la norma se relaciona con los cambios informales de la constitución", en Estudios Constitucionales 10 (2) (2012).

23 Heather K. Gerken, "The hydraulics of constitutional reform: A skeptical response to our undemocratic constitution", en Drake Law Review (2006), pp. 925-951.

$440 \quad 24$ Francisco Fernández, “Las mutaciones jurisprudenciales en la Constitución”, en Revista de las Cortes Generales (2013), pp. 7-88.

25 José Luis Leal y Carlos Cerda, "La mutación constitucional del principio de no intervención”, Cuestiones Constitucionales 35 (2016), pp. 81-118. 
Se debe mencionar que la doctrina formalista determina que la constitución debe ser interpretada según el análisis de la categoría lógico-formal, puesto que, si los intérpretes se dejan influenciar sesgadamente, estos no actuarían conforme al derecho y pondrían en peligro la seguridad jurídica. ${ }^{26}$ Los cambios informales van en contra de la teoría de la constitución, donde prevalece la teoría de la rigidez constitucional. Para Rollnert Liern, los cambios informales son "un fenómeno antitético como es el reconocimiento de la realidad de los cambios constitucionales operados al margen del procedimiento formal de revisión constitucional" ${ }^{27}$

Desde otra perspectiva, se puede decir que las mutaciones constitucionales no se contraponen con la corriente formalista, al contrario, el conflicto que puede surgir entre la Constitución y la realidad forma parte del proceso evolutivo de la Constitución:

La mutación constitucional no es ni quebrantamiento de la Constitución (Verfassungsbruch) ni simple regla convencional, sino que es derecho. Es derecho, aunque no concuerde con el tenor literal de la ley, es derecho, aunque no pueda ser captada ni conceptuada con los conceptos y construcciones jurídicas formales: su fundamento jurídico reside en la singularidad valorativa del derecho constitucional, en la llamada necesidad política, en las exigencias y manifestaciones de vitalidad del Estado que se realiza y se desarrolla a sí mismo. ${ }^{28}$

Es preciso observar que el proceso de reforma informal puede ocasionar ciertos problemas. El problema radica en que estos cambios son difíciles de advertir e incluso una vez advertidos, se vuelve complicado otorgarles un significado concreto. Asimismo, se complica la determinación de reglas que permitan establecer que, en efecto, se está frente a una norma que ha cambiado informalmente y que no se encuentra frente a simples cambios de tendencias políticas. ${ }^{29}$

Si bien existen posturas formalistas que determinan que las mutaciones constitucionales son cambios que carecen de legitimidad y que, al mismo tiempo, constituyen prácticas antidemocráticas, por el contrario, existen argumentos que contraponen esas posiciones y determinan que los cambios informales se vuelven inevitables especialmente en países que cuentan con mecanismos de reformas complejos, los cuales no permiten que la Constitución se adapte a la realidad cambiante de una sociedad, como en este caso se le puede atribuir a la Constitución del Ecuador.

26 Juan Manuel Goig, “La interpretación constitucional y las sentencias del Tribunal Constitucional: de la interpretación evolutiva a la mutación constitucional", en Revista de Derecho UNED 12 (2013), pp. 257-292.

27 Göran Rollnert Liern, "La mutación constitucional, entre la interpretación y la jurisdicción constitucional", en Revista Española de Derecho Constitucional 34 (101) (2014), p. 149.

28 Ana Victoria Sánchez, "Mutación constitucional y fuerza normativa de la Constitución. Una aproximación al origen del concepto", en Revista Española de Derecho Constitucional 20 (58) (2000), p. 132.

29 Gerken, "The hydraulics of constitutional reform: A skeptical response to our undemocratic constitution", op. cit. 
A pesar de que los cambios informales son complejos de identificar, existen estudios que determinan las diversas formas que pueden reformar informalmente la Constitución. Richard Albert realizó una clasificación de los mecanismos de reforma informal y los distinguió como convencionales y no convencionales. ${ }^{30}$ De la primera clasificación se pueden identificar la interpretación judicial como la más usual, la legislación nacional y la acción ejecutiva; en contraste, de la segunda clasificación se desprenden las reformas implícitas, la costumbre y el desuso.

Previo a analizar la posibilidad de cambio informal por desuso constitucional del primer inciso del artículo 422 de la Constitución del Ecuador, se debe abordar en qué consiste el desuso constitucional desde el punto de vista del derecho comparado.

\subsection{Desuso constitucional}

El desuso, en términos generales, es la derogación informal de un acto legislativo mediante un dictamen judicial; evidentemente, siempre que haya transcurrido un largo periodo de tiempo de no ejecución intencional y que, a su vez, haya existido conscientemente una inobservancia de dicho acto. ${ }^{31}$ En materia constitucional, Richard Albert y Carlos Bernal afirmaron que la norma "pierde su fuerza vinculante entre los actores políticos como consecuencia de la inaplicación consciente y constante, y además la repudiación de actores políticos del pasado y actuales". ${ }^{32} \mathrm{El}$ desuso constitucional es un tipo de cambio informal que ocurre cuando una norma deja de ser aplicada, lo cual se convierte en un simple enunciado derogado, carente de eficacia y validez, a diferencia de los otros tipos de cambio informal que modifican el texto. Se podría afirmar así que el cambio constitucional por desuso hace que la norma se entienda como inaplicable dentro del texto constitucional.

En correspondencia con esta idea, John Stinneford aseveró que "cuando una ley no se hace cumplir durante décadas a pesar de numerosas violaciones abiertas, esta falta de aplicación crea el riesgo de que el público se deje llevar por la creencia de que la ley ya no existe". ${ }^{33}$ Esta inobservancia permitiría que las normas fuesen desobedecidas por la sociedad, lo cual instaura el riesgo de que sean violadas y que su existencia se considere como innecesaria. Esto en tanto los actores políticos permiten su desobediencia e, incluso, no reaccionan ante violaciones frontales por parte de la ciudadanía. 
Para entender el cambio constitucional por desuso, se debe hacer un símil con el efecto que produce el uso prolongado de una norma. Así como este generaría el efecto de aceptación de la norma por parte de la sociedad, su desuso produciría un impacto opuesto. Sin embargo, Stinneford citó el ejemplo planteado por Edward Coke, en su comparación del uso prolongado de la norma con el refinamiento del oro al ser expuesto al fuego, quien establecía que, a medida que los casos se definían, el derecho, poco a poco, se refina hasta alcanzar la perfección. De esa manera, el "oro puro" de la ley prevalece mientras las "impurezas" o prácticas irracionales o inservibles se desechan. ${ }^{34}$

Así pues, con la finalidad de determinar que una norma ha caído en desuso, es necesario que haya dejado de ser acatada por un largo periodo de tiempo. A pesar de tener la facultad de ser aplicada por las autoridades, no ha sido ejercida de esta manera, por lo que se podría considerar que ha ocasionado una costumbre negativa relacionada con el uso de la norma. ${ }^{35}$ Esta concepción de costumbre negativa se remonta al concepto de Kelsen sobre el desuso, al establecer que este deja insubsistente la norma, dado que nunca fue acatada por la sociedad y fue inaplicada por sus actores políticos. ${ }^{36}$

\subsubsection{Antecedentes}

La doctrina del desuso es originaria del derecho civil y en la mayoría de los países aún no es reconocida, aunque Escocia es una de las excepciones que implementa formalmente esta teoría. ${ }^{37}$ Uno de los pioneros en los estudios del desuso es John Chipman, quien lo comentó como fuente del derecho dado que, a pesar de no estar escrito, es aceptado por la ciudadanía. Además explicaba que la costumbre, cuando se vuelve frecuente y obedecida por todos, se convierte en ley vinculante. Esto sucede pese a no estar plasmada en un texto normativo; de la misma manera, establecía que las leyes no necesariamente son derogadas mediante aprobación popular, su desaprobación puede permitir al juez invalidarla. ${ }^{38}$

En Estados Unidos, el cambio informal por desuso no ha sido del todo aceptado. En un momento determinado fue reconocido por la doctrina, pero oficialmente no se aceptó en todos los Estados. Para Peter Suber existían rastros de la aceptación de la teoría, el primero se encontraba en las normas de asociación de abogados estadounidenses vinculados con el rol de la Fiscalía, el cual establecía los factores que deben influir en la discreción de un fiscal. ${ }^{39}$ Uno

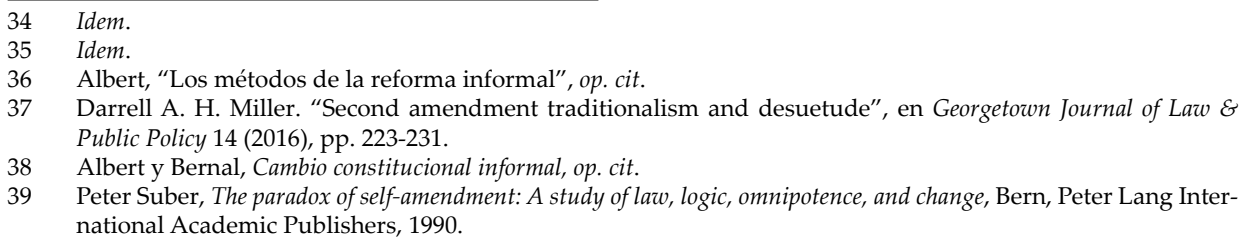


de estos era la no aplicación prolongada de una ley y el consentimiento de la comunidad; no obstante, aclaró que solo se trataba de lineamientos de política procesal y no de una regla de obligatorio cumplimiento para un tribunal.

El segundo rastro lo ubicaba en el caso Elliot versus Estados Unidos, en el que un acusado fue culpado de haber violado una ley antigua que se encontraba vigente y sin uso por más de 50 años; para este caso, el tribunal determinó válida la ley y, por ende, se incriminó al acusado ${ }^{40}$ Lo importante de este suceso es que en su resolución el juez manifestó que el desuso constitucional puede ser una defensa que tendría mucho poder si se la asocia al debido proceso o a la igualdad. Desde la emisión de este criterio en la sentencia Elliot, ningún juez se ha pronunciado al respecto del cambio informal por desuso ni ha invalidado una norma acogiéndose a este criterio. ${ }^{41}$

Con base en los casos expuestos, se puede evidenciar que ambos establecen lineamientos acerca de los efectos de la no aplicación de una norma por un tiempo prolongado. Igualmente, se puede entender la forma en que influía en determinado momento en la sociedad, lo que hace comprender que existe la posibilidad de que esta norma ya no deba ser acatada, debido a que no ha sido cumplida o utilizada por un periodo extenso de tiempo. Sin embargo, el criterio de temporalidad no es el único que debe observarse al momento de buscar determinar si una norma ha caído en desuso; sobre todo, tratándose de normativa constitucional a diferencia de cambios legales, la cual vuelve compleja su reforma y sería normal su prolongada duración invariable. A continuación, se revisan los otros elementos que deben concurrir para que una norma entre en desuso.

\subsubsection{Elementos característicos del desuso constitucional}

Para poder analizar si una norma ha caído en esta categoría de cambio informal, se debe tener en cuenta que el desuso se da de manera excepcional y que deben establecerse los siguientes elementos concurrentes: “1) la inaplicación consciente de una regla; 2) por un lapso relevante; $y$, 3) que ha sido repudiada públicamente por actores políticos". ${ }^{42}$

Conforme al primer elemento de la inaplicación consciente de la regla, Albert expuso que dicha inaplicación es imputable a nuevas costumbres o normas públicas. ${ }^{43}$ Estos casos se pueden dar mediante nuevas prácticas o adaptación a sucesos que han ocasionado que los actores políticos rechacen frontalmente la norma. Al respecto, David Law comentó que normalmente las constituciones

\footnotetext{
$40 \quad$ Idem.

41 The Harvard Law Review Association, "Desuetude", op. cit.

42 Albert y Bernal, Cambio constitucional informal, op. cit., p. 1

43 Idem.
} 
están sujetas a reglas que, en cierto momento, cumplieron sus funciones. ${ }^{44} \mathrm{No}$ obstante, en la actualidad, puede ocurrir que la norma no esté cumpliendo su función, dado que el sistema político así lo ha determinado. Para el autor, este tipo de normas se encuentran plasmadas en la constitución, pero se convirtieron en provisiones zombis que no cumplen una función. Además, para cualquier efecto, se encuentran como letra muerta, sin ningún impacto real o práctico.

Con relación al siguiente elemento, el primer caso estadounidense en el que claramente se empezó a discutir sobre el desuso fue el caso Thompson Co versus el distrito de Columbia. En esta situación, la Corte Suprema analizó las leyes antidiscriminación que regulaban los restaurantes en la época de la segregación, las cuales no habían sido discutidas o aplicadas por más de 75 años. En el segundo caso, Poe versus Ullman, la Corte Suprema realizó un análisis acerca del desuso de las leyes en Connecticut que prohibían el uso de anticonceptivos, la cual había sido promulgada 65 años atrás. En estos dos casos, lo destacable para el análisis del desuso no es el fondo del problema, lo que se trata de ilustrar es la cantidad de años que se discuten para el análisis de un cambio informal. ${ }^{45}$ Aunque no existe un plazo definido o un mínimo estricto de años para establecer que una norma ha caído en desuso, sí se requiere un largo periodo de tiempo con el cual se verifique que la sociedad rechaza la norma y que este rechazo no solo proviene de unas cuantas personas, sino que existe un consenso social de rechazo universal. ${ }^{46}$

En cuanto al tercer requisito, la norma que va a ser declarada en desuso debe ser rechazada por los actores políticos a través de una condena frontal, la cual consiste en establecer que la regla ya no es vinculante ni de cumplimiento obligatorio y no es necesario que sea acatada, puesto que el entorno político ha cambiado. ${ }^{47}$

\subsubsection{Desuso constitucional prematuro}

Uno de los elementos esenciales para detectar que una norma está en desuso se fundamenta en que ha transcurrido un lapso relevante. Sin embargo, esto no implica que dichas normas que dejan de ser utilizadas puedan ser detectadas prematuramente como desusos constitucionales. Un ejemplo claro es aquel en el que Richard Albert explicó la cláusula Not With Standing, la cual se encuentra en el artículo 33 de la Carta de Derechos y Libertades canadiense promulgada en $1982 .{ }^{48}$ Esta cláusula consiste en que el Parlamento o una legis-

\footnotetext{
44 David Law, "The myth of the imposed constitution", en Social and Political Foundations of Constitutions (2013), pp. 239-268.

45 Mark Peter Henriques, “Desuetude and declaratory judgment: A new challenge to obsolete laws", en Virginia Law Review 76 (5) (1990), pp. 1057-1097.

46 Stinneford, “Death, desuetude, and original meaning", op. cit.

47 Albert y Bernal, Cambio constitucional informal, op. cit.

48 Idem.
} 
latura provincial puede promulgar leyes que contengan elementos contrarios a la Carta de Derechos y Libertades canadiense, especialmente en lo relativo a la protección de libertades fundamentales y garantías jurídicas. Para dicha ocasión, puede utilizarse esta cláusula antes o incluso después del control de constitucionalidad para que la norma se mantenga válida por cinco años desde que se invoca y, a su vez, puede ser prorrogada en múltiples ocasiones.

En ese sentido, De Montalvo anotó que esta cláusula ha caído en desuso, debido a que el parlamento nunca la ha utilizado y que los actores políticos han desaprobado esta facultad. ${ }^{49}$ Además, ya no constituye un elemento fundamental en la Carta de Derechos y Libertades canadiense, dado que se trata simplemente de una prerrogativa excepcional que genera en los actores políticos una fuerte resistencia. El hecho de invocar esta cláusula evidenciaría que sus decisiones no consideran los derechos fundamentales de los ciudadanos y aplicarla provocaría desconfianza.

No obstante, la cláusula sí ha sido empleada como una potestad provincial, principalmente por Quebec, y ha sido invocada más de quince veces. ${ }^{50}$ Recientemente, en el año 2019 fue invocada por última vez en New Brunswick por el ministro de Educación, en un proyecto que buscaba obligar a las escuelas públicas y guarderías a presentar certificados de vacunaciones realizadas a los niños o exenciones debidamente suscritas por médicos. Se trajo a colación esa cláusula, con el objetivo de blindar la ley y prevenir que se alegue su inconstitucionalidad por ser contraria al derecho a la libertad de religión. Sin embargo, en junio de 2020, la cláusula Not With Standing fue unánimemente eliminada del proyecto de ley, puesto que, también, suprimiría la posibilidad de impugnarla por vía judicial. ${ }^{51}$

De ese modo, en el ejemplo de la cláusula canadiense Not With Standing se aprecia que la potestad federal, sin haber cumplido un plazo extenso, está cayendo en evidente desuso. Para Richard Albert y Carlos Bernal, esta norma ha generado de forma evolutiva una convención constitucional en contra de su uso..$^{52}$ Es innegable el rechazo de los actores políticos y su desaprobación la llevaría a que siga como inaplicada. David Law se refirió a ello y concluyó que "esta disposición no es parte de la práctica constitucional real; ha caído en desuso debido a su impopularidad entre el público". ${ }^{53}$

49 Federico de Montalvo, "Las cláusulas notwithstanding y override del constitucionalismo canadiense", en UNED. Teoría y Realidad Constitucional 30 (2012), pp. 387-409.

50 CBC News, “Canada's notwithstanding clause-what's that again?”, en CBC, 2018, https://www.cbc.ca/news/ canada/canada-constitution-notwithstanding-factsheet-ford-1.4817751

51 CTV News, "New Brunswick committee drops notwithstanding clause from vaccination bill”, en CTV, 2020,

446 https://atlantic.ctvnews.ca/new-brunswick-committee-drops-notwithstanding-clause-from-vaccination-

52 Albert y Bernal, Cambio constitucional informal, op. cit.

53 Law, "The myth of the imposed constitution", op. cit., p. 249. 


\subsubsection{Defectos del cambio informal por desuso}

La aplicación de una norma que ha caído en desuso crea un sentimiento de injusticia o inequidad y este puede ser identificado al revisar tres defectos legales. En primer lugar, se trata de una práctica que puede permitir discrecionalidad amplia a los operadores de justicia, lo cual, como consecuencia, crea potenciales actos injustos y selectivos. En segundo lugar, consiste en la falta de socialización de información relacionada con el desuso de la norma. En tercer lugar, es la aplicación forzosa de una norma completamente defectuosa para hacer respetar el texto de una ley sin reflejar su carácter de desueta. ${ }^{54}$

El desuso "plantea graves problemas de separación de poderes" ${ }^{55} \mathrm{y}$, al mismo tiempo, un conflicto de poder que podría surgir entre los órganos legislativo y judicial. Al tener el órgano judicial poder para determinar si una norma ha caído en desuso o no, estaría de cierta forma arrogándose funciones que solo le competen a la potestad exclusiva de los legisladores, por lo que los jueces no son los competentes para esta función y solo deben aplicarla. No obstante, existen argumentos en contra de esta postura, en tanto que la no aplicación de la norma es llevada a cabo por funcionarios que han sido democráticamente electos. Ante este panorama, la Corte podría tomar una decisión errónea si el desuso no proviniera de los actores políticos. ${ }^{56}$

\subsection{5. ¿Desuso constitucional del artículo 422?}

En cuanto a los cambios constitucionales, la constitución puede ser modificada formalmente de conformidad con los procedimientos prescritos en el texto constitucional o mediante mutaciones constitucionales que, sin modificar el texto, cambian únicamente el sentido de la norma, tal como se dejó establecido.

La Corte Constitucional del Ecuador, en su deber de interpretación, no solo debe limitarse a respetar la literalidad de la norma tal como lo establece el artículo 427 de la Constitución, "en caso de duda, se interpretarán en el sentido que más favorezca a la plena vigencia de los derechos", por lo que la labor de la Corte, como lo afirmó Pablo Alarcón "pretende que el intérprete no se limite a leer de manera aislada uno o varios preceptos constitucionales, pues aquello puede devenir en la privación de eficacia de otras disposiciones constitucionales. Es así como cualquier criterio de interpretación debe considerar reglas, valores y principios constitucionales". ${ }^{57}$

54 Erik Encarnación, "Desuetude-based severability: A new approach to old morals legislation", en Columbia Journal of Law and Social Problems 39 (2) (2005), pp. 149-184.

55 Henriques, "Desuetude and declaratory judgment: A new challenge to obsolete laws", op. cit., p. 1078

56 The Harvard Law Review Association, “Desuetude", op. cit.

Pablo Alarcón, Una metodología comparativa crítica aplicada al sistema constitucional ecuatoriano, Quito, Universidad Andina Simón Bolívar, Corporación de Estudios y Publicaciones, 2018, pp. 165-166. 
Así pues, la labor del juez constitucional, al interpretar la constitución, puede llevar a reformar la norma y generar un cambio de significado que permita una adaptación más eficaz a una realidad social que ha evolucionado. Claramente, siempre con un criterio imparcial que procure la prevalencia de derechos que favorezcan más a la sociedad.

En un estudio realizado por Christian Masapanta sobre las mutaciones de la Constitución del Ecuador, este autor demostró que desde su promulgación hasta 2018, la Corte Constitucional "ha emprendido en modificaciones al contenido de la constitución vía hermenéutica en sentido abstracto, en acciones de garantías jurisdiccionales de conocimiento de la Corte Constitucional, y en su competencia para desarrollar precedente jurisprudencial obligatorio mediante el proceso de selección y revisión constitucional". ${ }^{58}$

Esto se da al tener en cuenta que la Constitución es susceptible de ser reformada mediante cambios informales, y que los cambios más comunes son los realizados por medio de la interpretación judicial. De acuerdo con las diversas teorías de los autores revisados, una forma de interpretación del artículo 422 es que se trata de una norma que se encuentra en etapa de desuso constitucional, la cual ha perdido legitimidad y ha generado desaprobación de los actores políticos y de la sociedad. Por tanto, como resultado, deja de ser utilizada por completo.

La Constitución del Ecuador, en el artículo 422, primer inciso, establece: “No se podrán celebrar tratados o instrumentos internacionales en los que el Estado ecuatoriano ceda jurisdicción soberana a instancias de arbitraje internacional, en controversias contractuales o de índole comercial, entre el Estado y personas naturales o jurídicas privadas".$^{59}$

De tal forma, al tenor de lo literal, se puede entender que Ecuador no puede suscribir instrumentos internacionales en los que se contemple resolver controversias ante un tribunal arbitral internacional en materias contractuales y comerciales.

Dada esta interpretación literal, y con la finalidad de determinar si la norma podría encontrarse en desuso constitucional de acuerdo con la doctrina, es necesario mencionar la existencia de la acción de interpretación constitucional 0002-18-IC, presentada por la entonces presidenta de la Asamblea Nacional, Elizabeth Cabezas. En dicha interpretación consulta a la Corte Constitucional el alcance del artículo 422 y solicita que se interprete si la prohibición se debe

58 Christian Rolando Masapanta, Mutación de la Constitución del Ecuador. ¿La Corte Constitucional como constituyente permanente?, Quito, Universidad Andina Simón Bolívar, 2020, pp. 392-393.

59 Asamblea Nacional Constituyente del Ecuador, Constitución de la República del Ecuador, op. cit., art. 422. 
entender "cuando se celebren tratados de protección de inversiones en los que las controversias no sean contractuales ni comerciales". ${ }^{60}$

A partir de la vigencia de la Constitución de 2008, el expresidente Rafael Correa denunció todos los TBI. Estas denuncias fueron fundamentadas en que incurrían en la prohibición del artículo 422, con el propósito de precautelar la soberanía nacional. Ante las solicitudes de dictámenes de constitucionalidad en los procesos de denuncia, la Corte Constitucional mantuvo una línea de interpretación uniforme, tal argumento se evidenció en uno de los primeros instrumentos internacionales analizados por la Corte Constitucional, como es el "Acuerdo Internacional Celebrado entre el Gobierno Federal de Alemania y la República Federal de Alemania". ${ }^{61}$

Dicho TBI establecía la posibilidad de someter sus controversias a un tribunal arbitral internacional; en el dictamen de constitucionalidad se determinó:

No se puede permitir la creación de estos tribunales ad hoc para la solución de controversias que se suscitaren del presente tratado, porque iría en contra no solo de disposición constitucional expresa, sino que sería un atentado a la soberanía popular expresada a través de la constitución de la república atentándose el artículo 422 de la Constitución. ${ }^{62}$

La Corte Constitucional sostuvo que la única excepción permitida para la suscripción de instrumentos internacionales era la posibilidad de someter las controversias arbitrales a tribunales regionales con la "finalidad de impulsar la integración económica y el comercio regional", ${ }^{63}$ y que el sometimiento de estos arbitrajes internacionales fuera de la región no cumplía el objetivo de lograr el compromiso de integración latinoamericana.

La Corte Constitucional mantuvo esta línea de interpretación para todos los TBI denunciados por el Estado ecuatoriano, y rechazó el arbitraje internacional por atentar contra la normativa expresa y por ir en contra de los fines que se pretendían consolidar con la creación de un centro de arbitraje liderado por la región; sin embargo, en el año 2016 aparece la primera postura contraria, a través de un dictamen que permite apreciar los primeros rasgos de una posibilidad de cambio informal por desuso constitucional.

El dictamen referido es el 009-16-DTI-CC, el cual fue emitido el 12 de diciembre de 2016, mediante el cual se aprobó la adhesión de Ecuador al "Acuerdo Comercial entre la Unión Europea y sus Estados Miembros por una parte, y

\footnotetext{
60 Corte Constitucional del Ecuador, "IC - Interpretación de Normas Constitucionales, 0002-18-IC", op. cit.

61 Corte Constitucional del Ecuador, “Dictamen, 023-10-DTI-CC", 24 de junio de 2010 http://doc.corteconstitucional.gob.ec:8080/alfresco/d/d/workspace/SpacesStore/ef062fe3-a1c9-4f48-987e-5002ffdb1b17/0006-10-TI-res.pdf 
los Estados de Colombia y el Perú por otra, para tener en cuenta la adhesión de Ecuador". ${ }^{64}$ La Corte Constitucional, al llevar a cabo el control material en el dictamen, enunció que el acuerdo cuenta con 14 títulos, 337 artículos y 14 anexos, y que el protocolo de adhesión contiene 29 artículos y 20 anexos que forman parte de las obligaciones aplicables para el Ecuador.

La Corte, además, advirtió que "considerando la extensión del instrumento originario, su estructura, así como la extensión del protocolo adhesión", se referirían únicamente a las causales 3, 4 y 6 del artículo 419 de la Constitución que aluden, respectivamente; al compromiso de expedir, modificar o derogar una ley; a los casos que se refieren a los derechos y las garantías establecidas en la Constitución, en este caso solo se referiría específicamente a los derechos de propiedad intelectual, comercio y desarrollo sostenible; $y$, finalmente, a los compromisos que asume el país en acuerdos de integración y de comercio.

En su resolución, la Corte declaró la constitucionalidad del protocolo por ser compatible con la Constitución y, asimismo, aprobó en su integridad todos sus anexos, títulos y artículos que constituyen el acuerdo comercial. Al aprobar en su integridad el acuerdo, la Corte aceptó que el Ecuador se someta a lo contemplado en el título XII de solución de controversias, sin realizar un análisis de este. Cabe mencionar que en dicho título no se hace alusión a un arbitraje nacional y mucho menos regional, sino que se contempla un arbitraje regido bajo un comité de comercio que seguirá los parámetros de la Organización Mundial de Comercio (OMC). De este modo, en caso de controversias, el Ecuador puede ser sometido a un arbitraje internacional.

En virtud del dictamen emitido por la Corte Constitucional, se inicia una nueva interpretación y, con el cambio de Gobierno, surge una tendencia política a favor de esta tesis. De esta manera, para suscribir un TBI con China en el año 2018, la Asamblea Nacional solicitó una acción de interpretación del artículo 422 a la Corte Constitucional. ${ }^{65}$ Ese mismo año se expidió la Ley para el Fomento Productivo de Inversiones, la cual permite que el Ecuador suscriba contratos de inversión que contemplen la posibilidad de someter "jurisdicción soberana" a arbitraje internacional en contratos que superen los diez millones de dólares. Esta norma hace la distinción de que esta cesión de soberanía es para cuando se trate de contratos comerciales y no provenientes de cláusulas contempladas en los TBI.

Si bien el artículo 422 de la Constitución fue interpretado de manera restrictiva y literal por el gobierno del expresidente Correa y mantenía una línea ideológi-

64 Parlamento Europeo, Acuerdo comercial entre la Unión Europea y Colombia y Perú. Evaluación europea de la aplicación, op. cit.

65 Mayra Pacheco, "Negociación de los TBI, paralizada tras fallo de la anterior Corte Constitucional", en El Comercio, 2020, https://www.elcomercio.com/actualidad/negociacion-tbi-fallo-corte-constitucional.html 
ca en contra del arbitraje internacional, a partir del dictamen de 2016 se puede trazar claramente la forma en que nuevas costumbres políticas emergen, a tal punto que el Legislativo solicitó a la Corte Constitucional interpretar la norma mediante una acción interpretativa. Esto significa que, según los parámetros investigativos revisados, se podrá considerar que el artículo mencionado, en su interpretación literal, ya no goza de legitimidad como lo hacía a inicios del gobierno anterior.

Como se indicó, el desuso constitucional ocurre excepcionalmente y se da cuando una norma escrita deja de ser válida en el texto constitucional. En otras palabras, pasa a ser reemplazada por reglas que no se encuentran plasmadas en la Constitución. No obstante, es un proceso que se vuelve de complicada aplicación práctica en constituciones que tienen procedimientos rígidos de reforma, especialmente, en Ecuador.

Ahora bien, conforme a lo expuesto se podrían detectar rasgos característicos del cambio informal por desuso constitucional que reflejan una evidente incongruencia entre la realidad jurídica y la realidad política. Por una parte, hay una norma que establece de forma literal una prohibición de ceder jurisdicción soberana ante un órgano de arbitraje internacional y, por otra, se encuentra un acuerdo comercial con la Unión Europea suscrito en directa contradicción del artículo 422. Este es respaldado por un dictamen de constitucionalidad de la Corte Constitucional y, además, una nueva norma de rango legal que permite someter jurisdicción soberana.

Se debe aclarar que el Legislativo ha buscado, a través de un simple cambio semántico, evitar la prohibición contemplada en dicho artículo. Esto sucede, en parte, al incluir en la Ley de Fomento Productivo de reforma al Copci, la facultad de someter jurisdicción soberana cuando se trate de contratos de inversión. Dicha acción permite el arbitraje en dichos contratos, pero no de acuerdos bilaterales de inversión, lo cual puede considerarse como rechazo de la norma constitucional por parte de los actores políticos, con el fin de atraer la inversión extranjera al Ecuador. No obstante, el propósito originario de la inserción del artículo era que el Ecuador no se involucrara y no se sometiera a instancias de arbitraje internacional, sino que se fomentaba el arreglo de controversias en instancias nacionales o regionales.

A partir de los hechos relatados, que se vuelven necesarios para determinar si se está frente a un cambio informal por desuso constitucional, se deben examinar las tres condiciones necesarias y suficientes conforme a la doctrina.

El primer requisito para que la norma pierda su validez consiste en la inaplicación consciente de esta, para el caso, el artículo 422 de la Constitución, tal como se ha percibido. A pesar de estar expresada en el texto constitucional como una 451 prohibición que, si se observa al tenor de lo literal, se puede entender como 
absoluta, la Corte Constitucional ha permitido una interpretación distinta a la literal, apartándose de la línea de interpretación que se mantenía. De esta manera, se aprueba el sometimiento de Ecuador a cortes internacionales.

Esta interpretación constitucional que permite, a grandes rasgos, buscar una alternativa para promover inversiones y buscar una alternativa para evadir la prohibición del artículo en mención, es una muestra de pérdida de validez normativa. No es justificable buscar alternativas que permitan interpretaciones distintas a la literal, o solicitudes de interpretación constitucional si se encontrara legítimamente respaldada.

Como segunda condición, se instaura el repudio expreso de los actores políticos y de la sociedad. En la actualidad, lo que se puede ver reflejado no es un repudio de la norma, sino un cambio de postura gubernamental y se ha dejado a un lado la ideología que rechazaba al arbitraje de inversión. No se puede confundir un cambio de postura política con un rechazo expreso, dado que, como consecuencia de un cambio de tendencias, se podría desestabilizar el entorno político y modificarse cada vez que exista un nuevo gobierno que quiera imponer sus ideologías. Por ello, se vuelve indispensable que la norma que se pretenda declarar en desuso no solo sea rechazada, sino que haya transcurrido un plazo relevante y un repudio constante y manifiesto que permita determinar que se está frente a un cambio constitucional por desuso constitucional.

En relación con la característica de temporalidad necesaria para determinar que una norma ha caído en desuso constitucional, esta no se ha cumplido, pues, es evidente que no ha transcurrido un lapso relevante o estricto de años. No sería correcto afirmar que actualmente la norma ha caído en desuso constitucional desde la concepción tradicionalmente entendida, es imperante que haya trascurrido la no utilización de la norma por un periodo prolongado de tiempo para que pueda ser evidenciado el rechazo, tanto de los actores políticos como de la ciudadanía. En este caso, apenas han transcurrido cuatro años de un cambio de gobierno que no ha sido frontal respecto de la postura en contra del arbitraje de inversión.

Bajo ese entendido, David Law comentó que en su momento ciertas normas cumplen con un fin y después pasan a ser "provisiones zombis". ${ }^{66}$ Cuando fue promulgada la norma, se buscaba demostrar el rechazo al sistema arbitral de inversiones, que venía acompañado de una ideología política extremadamente proteccionista, sin observar un equilibrio que permitiera el fomento de la inversión extranjera. Sin embargo, en el momento político y económico que se encuentra el Ecuador, el actual gobierno buscó incentivar las inversiones

66 Law, "The myth of the imposed constitution", op. cit. 
extranjeras. Esta medida podría mantenerse y convertirse en una provisión zombi si no se busca una interpretación flexible de la norma.

De acuerdo con las condiciones analizadas, se puede precisar que no se está todavía frente a un cambio informal por desuso constitucional, pero sí se puede decir que, si la Corte Constitucional no realiza una interpretación que permita el equilibrio entre el fomento de inversiones y la protección del Ecuador ante posibles responsabilidades internacionales originadas por los TBIS, en un futuro se podría estar frente a un caso prematuro de cambio constitucional por desuso. En la práctica, es fundamental que, al momento de alegar un cambio informal, se contemple de manera irrestricta un argumento sólido que tenga en cuenta las condiciones suficientes y necesarias que permitan evitar discrecionalidades y conveniencias políticas con respecto a un desuso constitucional.

\section{Interpretación flexible}

Para solucionar el trilema se presenta una tercera alternativa, una interpretación flexible de la norma que permita el reconocimiento constitucional de que la cesión de soberanía no se configura por someterse a arbitraje internacional de inversiones. Lo anterior, según lo explicado, no constituye propiamente una cesión de soberanía y, por lo tanto, eliminaría la prohibición al tenor literal de la norma.

Esta interpretación sería limitable, por lo cual el Estado se compromete a someterse de manera potencial a jurisdicciones de arbitraje internacional. En casos específicos, no de forma permanente e ilimitada, sino transitoria, el Estado puede siempre limitar sus negociaciones, suscribir o no el tratado si lo cree conveniente y, en caso de adherirse o suscribirlo, puede denunciarlo.

Además, esta interpretación flexible debe eliminar la posibilidad de acogerse a tratados internacionales de inversión de forma inmotivada. Se deben considerar parámetros de respeto de derechos humanos y sociales y, especialmente, limitar las potenciales reclamaciones desproporcionadas por medio de cláusulas ambiguas. Por ende, la interpretación flexible deberá reflejar un profundo análisis del TBI que, por un lado, elimine el riesgo sin límites de responsabilidad internacional $y$, por otro, vele por objetivos que fomenten responsablemente la inversión extranjera.

En caso de que la Corte Constitucional realice una interpretación flexible del artículo 422 que permita al Estado ecuatoriano someter a jurisdicción internacional las disputas provenientes de un tratado de inversión debe, en cada uno de los tratados subsiguientes, mantener estándares de protección de derechos a través de un análisis minucioso de las cláusulas de los tratados que, al mismo tiempo, permitan la defensa de los intereses del Estado. 
Así es como la Corte Constitucional tiene un rol preponderante al momento de realizar el control de constitucionalidad de los tratados. Como referencia de protección de inversiones sobresalen los lineamientos que se dieron con base en la Sentencia C-252 de 2019 emitida por la Corte Constitucional colombiana que ha creado un precedente de discusión, a raíz de la crisis del sistema de inversiones. Para contextualizar, en el momento en que se resolvió este fallo se encontraban pretensiones por parte de procesos provenientes de celebración de TBI que "pretendían alcanzar indemnizaciones que sumaban USD 9.525 millones, valor superior al 10 por ciento del total del presupuesto nacional colombiano para el año $2019^{\prime \prime}{ }^{67}$

\subsection{Análisis de la Sentencia C-252 de 2019 de la Corte Constitucional colombiana}

Una sentencia que define parámetros actuales que los Estados deben tener en cuenta al momento de firmar un TBI y analizar las consecuencias de someter a un Estado al sistema arbitral internacional de inversiones es la emitida por la Corte Constitucional colombiana el 6 de junio de 2019, respecto al Acuerdo sobre el Fomento y la Protección Recíproca de Inversiones entre Colombia y Francia.

La Corte Constitucional llevó a cabo un juicio de razonabilidad que consiste en determinar que las finalidades del tratado sean compatibles y legítimas con la Constitución. Además, que exista suficiente evidencia que permita prever que el tratado va a alcanzar las finalidades deseadas. Aunque los jueces no lograron determinar suficiente evidencia que sustente que el tratado genere más inversión extranjera, no hay pruebas que demuestren lo contrario.

Entonces, la Sentencia C-252 de 2019 estableció, por parte de los jueces constitucionales, una nueva concepción; se dejó un lado la doctrina Calvo y se determinó dar autoridad a los árbitros de inversión. Cabe aclarar que dicha sentencia tiene dos características que conducen a un cambio de enfoque: en primer lugar, es pluralista al permitir el debate y abrir las puertas a todos los grupos de interés que quisieron impartir criterios a favor y en contra, con la finalidad de resolver y determinar un mejor criterio del acuerdo internacional de inversiones y del derecho. En segundo término, esta interpretación puede imponer parámetros de negociación que repercuten en futuros acuerdos o, incluso, en cortes de la región. ${ }^{68}$

$67 \quad$ Federico Suárez, "Sentencia C-252 del 2019 de la Corte Constitucional de Colombia: Cambio de precedente en el control a los TBI", en Investment Treaty News, 2019, https://cf.iisd.net/itn/es/2019/09/19/judgmentc-252-of-2019-of-the-constitutional-court-of-colombia-change-of-precedent-on-the-control-of-bits-federicosuarez-ricaurte/

68 Gustavo Prieto, “EJIL: Talk! Blog of the European Journal of International Law”, en Ejil: Talk!, 2019, https://www. ejiltalk.org/the-colombian-constitutional-court-judgment-c-252-19-a-new-frontier-for-reform-in-international-investment-law/ 
Un punto que se debe resaltar para el análisis de esta investigación es el relativo al artículo 15 del Acuerdo acerca del "arreglo de diferencias entre un inversionista y una parte contratante". En este artículo se establecen 24 puntos, de los cuales se destaca que se deben negociar de manera amigable por un tiempo máximo de seis meses desde que se generó el conflicto. En caso de no resolverse así, el inversionista podrá acudir ante un tribunal competente o ante un tribunal internacional, en el que solo podrá presentarse un inversionista que no posea doble nacionalidad. Además, no pueden haber transcurrido más de cuatro años desde la notificación de la vulneración y se debe estar sujeto a lo establecido por el Reglamento de la Comisión de las Naciones Unidas para el Derecho Mercantil (CNUDMI) sobre transparencia. El laudo será único y el tribunal estará compuesto por tres árbitros, uno que sea escogido por cada parte y el tercero en conjunto. Antes de dictar su decisión, el tribunal comunicará a las partes su propuesta, para lo cual los involucrados podrán presentar sus comentarios ante el tribunal.

Con respecto a esto, la Corte Constitucional declaró la exequibilidad de este artículo y precisó que el mecanismo de arreglo de diferencias no viola el principio de igualdad, por lo que no se otorga más protección a los inversionistas extranjeros que a los nacionales $y$, sumado a esto, no vulnera el principio de transparencia, puesto que el procedimiento se sometería al reglamento de la CNUDMI sobre transparencia en el proceso. En términos sencillos, garantiza su publicidad en las diferentes etapas procesales. Un detalle importante es la aclaración de voto del magistrado Carlos Bernal Pulido sobre la cláusula antes señalada de arreglo de diferencias, en la que estableció:

... que la sala plena ha debido pronunciarse en relación con (i) la aplicación del reglamento de la CNUDMI sobre la transparencia en los arbitrajes entre inversionistas y estados, (ii) el límite de las indemnizaciones ordenadas en los eventuales laudos proferidos por los tribunales de arbitraje internacional de inversiones que se constituyan con base en este tratado y (iii) las implicaciones de la sentencia del caso Slovak Republic v Achmea B.V, proferida, el 7 de marzo de 2018, por el Tribunal de Justicia de la Unión Europea. ${ }^{69}$

Sobre esta aclaración de voto, solo se hace referencia a los dos primeros puntos. En primera instancia, es fundamental resaltar la consideración del magistrado Bernal relacionada con no contemplar un escenario en caso de negación de sometimiento al reglamento de la CNUDMI sobre la transparencia del arbitraje. Por este motivo, quedan dudas de cuál será la real protección de transparencia en un eventual proceso arbitral en caso de ser rechazado el reglamento por la contraparte. Los Estados deben contemplar estándares de transparencia que permitan establecer procedimientos claros, los cuales deben garantizar el acceso

69 Corte Constitucional de la República de Colombia, Sentencia C-252, op. cit., preámbulo. 
a la información, especialmente cuando se involucre patrimonio de dominio público. Por lo anterior, la Corte deberá contemplar estos estándares que deben ser obligatorios y no dejar a discrecionalidad de la contraparte adherirse o no. En contraste, el segundo apartado resuelve que la Sala ha debido tener en cuenta para determinar las reglas de indemnización de los tribunales arbitrales los principios de seguridad jurídica, igualdad y sostenibilidad. Es importante reiterar que, precisamente, uno de los motivos de rechazo al sistema arbitral de inversiones radica en que no se han previsto ni se han establecido montos máximos de indemnización. Entonces, no es posible la no limitación de las indemnizaciones que pueden ser excesivas o desproporcionadas y que, sin lugar a dudas, podrían afectar la economía del país.

A raíz de este fallo, la Corte impuso estándares de revisión de los tratados que llevaron a resolver una declaratoria de exequibilidad condicionada, con el fin de realizar una declaración interpretativa entre Francia y Colombia. Igualmente, se intentó resolver acerca de cláusulas del tratado que podrían ser perjudiciales para los intereses colombianos y disminuir futuros impactos que puedan llevar a condenas perjudiciales para el Estado.

Refiriéndose a esta sentencia, Tamayo-Álvarez sostuvo que "la importancia de la Sentencia reside en la articulación de un estándar de revisión, un verdadero cambio de paradigma en el control constitucional de los AII". ${ }^{70}$ La convocatoria a audiencia pública por parte de la Corte Constitucional es algo que sin duda muchos autores han destacado. Resulta relevante que profesionales, funcionarios y, en general, grupos interesados en materia de inversiones y en el desarrollo de una nación puedan aportar y desarrollar esta rama del derecho que al día de hoy se encuentra en una etapa crítica.

De esa forma, se puede observar un análisis relacionado con el fomento de estándares de responsabilidad social corporativa. El hecho de exigir este tipo de responsabilidad a las empresas multinacionales que van a ser parte de una sociedad foránea permite el cumplimiento de principios constitucionales y precautela la no violación de derechos humanos, temas que se han vuelto recurrentemente criticados y muchas veces juzgados por no precautelar estos derechos.

En definitiva, los servidores del Estado deben procurar, en todo momento, salvaguardar los principios constitucionales y también tener en cuenta que se debe velar principalmente por cumplir el debido proceso. Los instrumentos internacionales deben incluir reglas de transparencia procesal, contemplar la imparcialidad de los árbitros y, asimismo, que no se discrimine al inversionista nacional y que siempre prevalezca la sostenibilidad fiscal de un Estado.

70 Rafael Tamayo-Álvarez, "Constitutionality of the Colombia-France bilateral investment treaty", en American Journal of International Law 114 (3) (2020), p. 471. 


\section{Conclusión}

Por las consideraciones expuestas, se puede plantear que el artículo 422 de la Constitución podría, en un futuro, encontrarse en una etapa prematura de cambio constitucional por desuso. Independientemente de la clasificación académica de desuso, lo exacto e inequívoco es que una interpretación literal y amplia de este artículo, que implique la inconstitucionalidad de todos los instrumentos internacionales y que, igualmente, incorpore un mecanismo de resolución de controversias en el que someta a organismos internacionales es, en definitiva, una interpretación fuera de toda lógica. Este hecho ha sido verificado por la Corte Constitucional, que ha interpretado la norma y permitido que coexistan instrumentos internacionales como el acuerdo de la Unión Europea.

Cabe señalar que las razones para que la Corte Constitucional permita estos tratados en contradicción con la literalidad de la norma son las siguientes: 1) cuando el Estado suscribe los tratados de inversión ejerce soberanía no cediéndola; 2) si el Estado acepta someterse a una jurisdicción soberana en materia arbitral debe contemplar siempre que el instrumento internacional sea revisado y condicionado, que sea temporal y bajo ciertos parámetros o reglas de negociación.

En todo caso, el artículo 422 tiene una génesis políticamente justificada, la prevención del perjuicio del Estado a través de mecanismos de solución de controversias que violen el debido proceso, la transparencia, la imparcialidad y el principio de igualdad entre el inversionista nacional y extranjero. En general, medidas que atenten contra la sostenibilidad fiscal con condenas desproporcionadas.

A pesar de ello, el perjuicio que causa esta prohibición es, probablemente, en términos económicos, más perjudicial para Ecuador que los fines que persigue al evitar la imposición de laudos con cuantías desproporcionadas. Así, se ha verificado que el beneficio de contar con inversión extranjera es sumamente elevado en términos numéricos.

Finalmente, se ha planteado una opción flexible que elimine la interpretación absoluta y literal de la prohibición constitucional, puesto que se evidenció que no hay cesión de soberanía. Por lo tanto, si se realiza un ejemplar control de constitucionalidad, como el referente colombiano, se pueden eliminar en su mayoría los perjuicios que se ha buscado prevenir al firmar un acuerdo bilateral de inversiones. 


\section{Bibliografía}

Alarcón, Pablo, Una metodología comparativa crítica aplicada al sistema constitucional ecuatoriano, Quito, Universidad Andina Simón Bolívar, Corporación de Estudios y Publicaciones, 2018.

Albert, Richard y Carlos Bernal, Cambio constitucional informal, Bogotá, Universidad Externado de Colombia, 2017.

Albert, Richard, "Los métodos de la reforma informal", en Revista Latinoamericana de Derecho 3 (2019), pp. 29-47. DOI: https://doi.org/10.29263/lar03.2019.02

Asamblea Nacional Constituyente del Ecuador, Constitución de la República del Ecuador, Quito, 2008.

Carpizo, Jorge, "La soberanía del pueblo en el derecho interno y en el internacional", en Revista de Estudios Políticos (Nueva Época) 28 (1982), pp. 195-209.

CBC News, "Canada's notwithstanding clause-what's that again?", en $C B C$, 2018, https://www.cbc.ca/news/canada/canada-constitution-notwithstanding-factsheet-ford-1.4817751

Centro de Derechos Económicos y Sociales, "Amicus curiae para impedir nuevos TBI", en CDES, 2020, https://cdes.org.ec/web/amicus-curiae-para-impedir-nuevos-tbi/

Corte Constitucional de Colombia, Sala Plena, Sentencia C-252 de 6 de julio de 2019, M. P. Carlos Bernal Pulido, https://www.corteconstitucional.gov. co/relatoria/2019/c-252-19.htm

Corte Constitucional del Ecuador, "Dictamen, 023-10-DTI-CC", 24 de junio de 2010. Recuperado de: http://doc.corteconstitucional.gob.ec:8080/alfresco/ d/d/workspace/SpacesStore/ef062fe3-a1c9-4f48-987e-5002ffdb1b17/000610-TI-res.pdf

Corte Constitucional del Ecuador, “IC - Interpretación de Normas Constitucionales, 0002-18-IC", 16 de agosto de 2018, https://portal.corteconstitucional. gob.ec/FichaCausa.aspx?numcausa=0002-18-IC

CTV News, "New Brunswick committee drops notwithstanding clause from vaccination bill", en CTV, 2020, https://atlantic.ctvnews.ca/new-brunswickcommittee-drops-notwithstanding-clause-from-vaccination-bill-1.4987933

De Montalvo, Federico, "Las cláusulas notwithstanding y override del constitucionalismo canadiense", en UNED. Teoría y Realidad Constitucional 30 (2012), pp. 387-409. DOI: https://doi.org/10.5944/trc.30.2012.7013 
Encarnación, Erik, "Desuetude-Based severability: A new approach to old morals legislation", en Columbia Journal of Law and Social Problems 39 (2) (2005), pp. 149-184.

Fernández, Francisco, "Las mutaciones jurisprudenciales en la Constitución", en Revista de las Cortes Generales (2013), pp. 7-88. DOI: https://doi. org/10.33426/rcg/2013/89/723

Gerken, Heather K., “The hydraulics of constitutional reform: A skeptical response to our undemocratic constitution", en Drake Law Review (2006), pp. 925-951.

Goig, Juan Manuel, “La interpretación constitucional y las sentencias del Tribunal Constitucional: de la interpretación evolutiva a la mutación constitucional", en Revista de Derecho UNED 12 (2013), pp. 257-292.

Henriques, Mark Peter, “Desuetude and declaratory judgment: A new challenge to obsolete laws", en Virginia Law Review 76 (5) (1990), pp. 1057-1097. DOI: https://doi.org/10.2307/1073157

Hillgruber, Cristian, "Soberanía - La defensa de un concepto jurídico", en inDret Revista para el Análisis del Derecho 1 (2009), pp. 1-20.

ISDS América Latina, "Impactos ISDS”, en ISDS, 2019, https://isds-americalatina.org/en-numeros/

Law, David, "The myth of the imposed constitution", en Social and Political Foundations of Constitutions (2013), pp. 239-268. DOI: https://doi.org/10.1017/ CBO9781139507509.013

Leal, José Luis y Carlos Cerda, "La mutación constitucional del principio de no intervención", Cuestiones Constitucionales 35 (2016), pp. 81-118.

Masapanta, Christian Rolando, Mutación de la Constitución del Ecuador. ¿La Corte Constitucional como constituyente permanente?, Quito, Universidad Andina Simón Bolívar, 2020.

Mena Erazo, Paul, "Ecuador pone fin a tratados bilaterales de inversiones", en BBC News, 2010, https://www.bbc.com/mundo/economia/2010/09/100915_ ecuador_fin_tratados_bilaterales_inversiones_jp

Miller, Darrell A. H., "Second amendment traditionalism and desuetude", en Georgetown Journal of Law \& Public Policy 14 (2016), pp. 223-231.

Pacheco, Mayra, "Negociación de los TBI, paralizada tras fallo de la anterior Corte Constitucional", en El Comercio, 2020, https://www.elcomercio.com/ actualidad/negociacion-tbi-fallo-corte-constitucional.html 
Parlamento Europeo, Acuerdo comercial entre la Unión Europea y Colombia y Perú. Evaluación europea de la aplicación, Estrasburgo, Servicio de Estudios del Parlamento Europeo, 2018.

Prieto, Gustavo, “EJIL:Talk! Blog of the European Journal of International Law", en Ejil: Talk!, 2019, https://www.ejiltalk.org/the-colombian-constitutional-court-judgment-c-252-19-a-new-frontier-for-reform-in-international-investment-law/

Rollnert Liern, Göran, “La mutación constitucional, entre la interpretación y la jurisdicción constitucional", en Revista Española de Derecho Constitucional 34 (101) (2014), pp. 125-155.

Sant'Ana, Adriano, “Mutación constitucional y concreción normativa: cómo la estructura de la norma se relaciona con los cambios informales de la constitución", en Estudios Constitucionales 10 (2) (2012), pp. 369-390. DOI: https://doi.org/10.4067/S0718-52002012000200009

Sánchez, Ana Victoria, "Mutación constitucional y fuerza normativa de la Constitución. Una aproximación al origen del concepto", en Revista Española de Derecho Constitucional 20 (58) (2000), pp. 105-135.

Schultz, Thomas y Cédri Dupont, "Investment arbitration: Promoting the rule of law or over-empowering investors? A quantitative empirical study", en The European Journal of International Law 25 (4) (2015), pp. 1148-1168. DOI: https://doi.org/10.1093/ejil/chu075

Sierra, Jimena, “Los riesgos del ISDS en tiempos de pandemia”, en Ámbito Jurídico, 2020, https://www.ambitojuridico.com/noticias/etcetera/educaciony-cultura/los-riesgos-del-isds-en-tiempos-de-pandemia

Solórzano Quintero, Juan Felipe, "Los tratados bilaterales de protección de inversiones y su sometimiento a los derechos humanos y un breve excursus para el caso colombiano", en Revista de Estudios Sociojurídicos 19 (2) (2017), pp. 223-258. DOI: https://doi.org/10.12804/revistas.urosario.edu. co/sociojuridicos/a.5256

Stinneford, John, "Death, desuetude, and original meaning", en William and Mary Law Review 56 (2) (2014), pp. 531-595.

Suárez, Federico, "Sentencia C-252 del 2019 de la Corte Constitucional de Colombia: cambio de precedente en el control a los TBI", en Investment Treaty News, 2019, https://cf.iisd.net/itn/es/2019/09/19/judgment-c-252-of-2019-ofthe-constitutional-court-of-colombia-change-of-precedent-on-the-controlof-bits-federico-suarez-ricaurte/

Suber, Peter, The Paradox of Self-Amendment: A Study of Law, Logic, Omnipoten$c e$, and Change, Bern, Peter Lang International Academic Publishers, 1990. 
Tamayo-Álvarez, Rafael, "Constitutionality of the Colombia-France bilateral investment treaty", en American Journal of International Law 114 (3) (2020), pp. 471-478. DOI: https://doi.org/10.1017/ajil.2020.37

The Harvard Law Review Association, "Desuetude", en Harvard Law Review 119 (7) (2006), pp. 2209-2229.

Van Harten, Gus, "Five justifications for investment treaties: A critical discussion", en Forthcoming 2 (1) (2010), pp. 1-32. DOI: https://doi.org/10.2139/ ssrn. 1622928

Van Harten, Gus, "Is it time to redesign or terminate investor-state arbitration?", en Osgoode, 2017, https://digitalcommons.osgoode.yorku.ca/scholarly_works/2629/

Vita, Leticia, “Soberanía y derecho internacional en el pensamiento jurídico de Weimar", en Journal of International Law 3 (1) (2012), pp. 7-24. 